Boise State University

ScholarWorks

Counselor Education Faculty Publications and

Presentations

Department of Counselor Education

$7-1-2016$

Training Elementary School Students to Intervene as Peer-Advocates to Stop Bullying at School: A Pilot Study

\author{
Aida Midgett \\ Boise State University \\ Diana M. Doumas \\ Boise State University
}


This is an author-produced, peer-reviewed version of this article. The final, definitive version of this document can be found online at

Journal of Creativity in Mental Health, published by Routledge. Copyright restrictions may apply. doi: 10.1080/15401383.2016.1164645

\title{
Training Elementary School Students to Intervene as Peer- Advocates to Stop Bullying at School: A Pilot Study
}

\author{
Aida Midgett \\ Boise State University \\ and \\ Diana M. Doumas \\ Boise State University
}

Citation: Midgett, A., \& Doumas, D. M. (2016). Training Elementary School Students to Intervene as PeerAdvocates to Stop Bullying at School: A Pilot Study. Journal of Creativity in Mental Health, 11, 353-365.

\begin{abstract}
The prevalence of bullying among children has prompted the development of school- based programs to address this problem. This pilot study evaluated the effectiveness of a brief, standalone bystander bullying program for elementary school students. The purpose to the program was to train students to take action as peer-advocates. After completing the 75-minute program, students reported an increase in their ability to identify what different types of bullying look like, knowledge of bystander intervention strategies, and general confidence intervening as peer-advocates. Furthermore, fifth grade students showed the greatest response to the program. Implications for school counselors as leaders in program implementation and future directions for research are discussed.
\end{abstract}

Keywords: bullying, bystander program, elementary school, peer-advocates, STAC

Bullying in schools is a significant national social problem. Bullying begins to escalate in late elementary school, suggesting there is a need for elementary school counselors to provide bullying programs for this age group. Although comprehensive, school-wide interventions can be effective in reducing bullying, many schools do not have the resources to implement these programs. Brief bystander programs that train students to be peer-advocates provide a promising, cost-effective approach to bullying intervention. The purpose of this study is to evaluate the effectiveness of a brief, stand- alone bystander program on students' ability to identify different types of bullying behavior, knowledge of peer-advocate strategies that can be used by bystanders, and confidence intervening when they observe bullying behavior.

\section{The Problem of Bullying}

Bullying is a major problem youth face in the United States (American Educational Research Association, 2013). Bullying often occurs in the school setting, with more than 5.3 million students reporting being bullied at school in 2013 (U.S. Department of Education, 2015). Further, being a target of bullying is associated with both emotional and academic difficulties such as low self-esteem and depression (Rueger \& Jenkins, 2014), suicidal ideation and attempts (Klomek, Marrocco, Kleinman, Chnonfeld, \& Gould, 2007) and decreased school attendance and lower grades (Rueger \& Jenkins, 2014).

Problems associated with bullying are not limited to students who are bullied. Bullying also impacts students who witness bullying behaviors, often referred to as bystanders. Researchers have found that bystanders are at greater risk of substance abuse than students who are bullied, and are at higher risk of negative nonclinical outcomes than students who bully (Rivers, Poteat, Noret, \& Ashurt, 2009). This is particularly important as more than two thirds of students report observing bullying at school (Rivers et al., 2009). 
This is an author-produced, peer-reviewed version of this article. The final, definitive version of this document can be found online at Journal of Creativity in Mental Health, published by Routledge. Copyright restrictions may apply. doi: 10.1080/15401383.2016.1164645

\section{Bullying in Elementary School and the Role of the School Counselor}

Research indicates bullying begins to increase in late elementary school (Pelegrini \& Long, 2012). In a study focusing specifically on bullying among elementary school students, researchers found that $22 \%$ of students report being involved in bullying either as a target, a bully, or both (Glew, Fan, Katon, Rivara, \& Kernic, 2005). Among this sample of students, being a target of bullying was associated with lower achievement, feeling unsafe, feeling as if one does not belong at school, and feeling sad. Thus, although bullying escalates as students transition to middle school, it is important to recognize that bullying needs to be addressed in elementary school settings as well.

All 50 states have laws governing bullying that require school personnel to protect students and take action against bullying (U.S. Department of Health and Human Services, 2015). According to the American School Counselor Association National Model (ASCA, 2012), one role for school counselors is to be leaders in promoting student achievement through the delivery of school-wide initiatives that support the academic, career and personal/social development of all students. This role includes providing programs that promote a safe learning environment. School counselors can take on a leadership role in ensuring bullying is addressed to create a safe climate that is conducive to student learning. Thus, an important role for the school counselor is effectively implementing programs that reduce bullying.

\section{The Role of the Bystander}

Students who observe bullying can behave in different ways in response to witnessing a bullying incident. These responses have been categorized as bystander roles that include "assistants" who actively and directly help the bully victimize a target, "reinforces" who laugh at or simply witnesses the situation, "outsiders" who do not take sides and often disengage or walk away from the group in order to dismiss the situation, and "defenders" who intervene and/or console the target of bullying (Salmivalli, Lagerspetz, Björkqvist, Österman, \& Kaukiainen, 1996, p.15).

Researchers have found an association between bystander behavior and bullying (Salmivalli, Voeten, \& Poskiparta, 2011). Specifically, researchers found that when bystanders reinforce the bully, bullying behavior increases; in contrast, when bystanders intervene or defend the target, bullying behavior decreases. Because most students are exposed to bullying as a bystander at some point in time (Rivers et al., 2009), bystanders are an important aspect of bullying intervention programs that need to be better understood and utilized (Bradshaw, 2015; Polanin, Espelage \& Pigott, 2012). In particular, equipping bystanders with strategies they can use to become "defenders" represents a promising approach for bullying prevention.

\section{$\underline{\text { School-Wide Bystander Interventions }}$}

The standard for practice for school-based bullying interventions are comprehensive, school-wide programs that include administrators, teachers, students, and parents engaging in a variety of roles to reduce bullying. Many of these programs include a bystander intervention component designed to teach students to intervene when they observe bullying behaviors. Results of a recent meta-analysis support the effectiveness of school-based programs that incorporate bystander interventions in reducing bullying (Polanin et al., 2012).

Bully-proofing (Garrity, Jens, Porter, Sager \& Short-Camilli, 2004) is an example of a comprehensive, school-wide program that involves training administrators, staff, teachers, bystanders, and parents to address bullying. Bullyproofing includes a bystander component in which teachers train students to intervene when they observe bullying as part of their classroom curriculum. Students are taught the CARES strategies which include, "creative problem solving," "adult help," "relate and join," "empathy”, and "stand up and speak out” (Garrity et al., 2004, p.117). In a recent study examining the effectiveness of bully-proofing, the program was associated with decreased rates of victimization and perpetration relative to a control group (Menard \& Grotpeter, 2014).

Additionally, students participating in the bully-proofing program reported higher perceptions of school safety during program implementation. Although effective, implementation of bully-proofing includes a minimum of 15 hours of teacher preparation and 270 days of program implementation for students and teachers (Menard \& Grotpeter, 2014). This is not uncommon for comprehensive, school-wide programs. Thus, it is important to identify empirically supported interventions that are brief and can be implemented with limited resources. 
This is an author-produced, peer-reviewed version of this article. The final, definitive version of this document can be found online at Journal of Creativity in Mental Health, published by Routledge. Copyright restrictions may apply. doi: 10.1080/15401383.2016.1164645

\section{Brief Bystander Interventions}

In contrast to comprehensive, school-wide interventions, brief bystander interventions can be implemented in a shorter amount of time with fewer personnel, thereby having the potential to be adopted by schools with limited resources. There is preliminary evidence suggesting that brief, school-based programs that include a bystander intervention component are a promising alternative to comprehensive, school- wide interventions (Evers, Prochaska, \& Van Marter, 2007; Andreou, Didaskalou, \& Vlachou, 2008). In one study, researchers examined the effects of training students during three, 30-minute online sessions. A 10-page Family Guide and Staff Guide was also provided to participants' families and teachers. Results showed the intervention was associated with a decrease in student participation in bullying. In another study, researchers examined an eight-hour teacher-delivered bystander curriculum adapted from a comprehensive, school-wide program (Andreou, Didaskalou, \& Vlachou, 2008). Results indicated the program was effective in changing attitudes toward bullies and victims, increasing students' perceived efficacy in intervening in bullying incidents, and increasing rates of intervening behaviors.

\section{Shifting Bullying Programs from Teachers to School Counselors}

Teachers within the classroom curriculum instruct the majority of bystander interventions. Shifting program implementation from teachers to school counselors is also important (Mariani, Webb, Villares, \& Brigman, 2015). The ASCA model promotes the role of school counselors as systemic change agents, suggesting that school counselors should take a leadership role in promoting and implementing bullying programs. Additionally, because there are already high demands placed on teachers, a leadership role in program implementation may be better suited for school counselors who are invested in promoting student wellness. Thus, school counselors are well poised to become bullying prevention and intervention leaders, promoting and coordinating program implementation at their school.

In a recent study, researchers investigated a brief, stand-alone counselor-led bystander program, STAC, designed for middle school students (authors, in press). The STAC program, adapted from the CARES component of bullyproofing, is developed to train bystanders to intervene as peer-advocates using the STAC strategies "stealing the show," "turning it over," "accompanying others," and "coaching compassion." The STAC program was created specifically for school counselors to coordinate program implementation without relying on teacher instruction. Result of this study showed that the STAC program was effective in training middle school students to be peeradvocates. Specifically, at post-test, students' reported an increase in their ability to identify different types of bullying behavior, knowledge of the STAC strategies, and general confidence intervening in bullying situations.

\section{The Current Study}

Because bullying behavior begins to escalate in elementary school, there is a need to equip elementary school students to be peer-advocates. This pilot study serves as a first step in extending the literature by evaluating the effectiveness of a counselor-based training program among elementary students. Specifically, we evaluated the effectiveness of the STAC program to teach elementary school students to identify bullying behaviors and specific strategies they can use to intervene as peer-advocates. We hypothesized that students would report an increase in their (a) ability to identify bullying behaviors, (b) knowledge of the STAC strategies, and (c) confidence in intervening from pre-test to post-test.

We were also interested in whether there would be differences in outcomes by grade level. Researchers have found that students in fifth grade differentiate aggressive and prosocial behaviors at a higher level than students in third grade (Sullivan \& Stoner, 2011). Therefore, another aim of this pilot study was to examine grade level as a moderator of program effects, thereby investigating if there is an optimal grade level when students are more likely to benefit from being trained as peer-advocates. 
This is an author-produced, peer-reviewed version of this article. The final, definitive version of this document can be found online at Journal of Creativity in Mental Health, published by Routledge. Copyright restrictions may apply. doi: 10.1080/15401383.2016.1164645

\section{Methods}

\section{$\underline{\text { Participants }}$}

Elementary school students from two Northwestern schools were recruited during the spring semester. The school counselor selected between 8-12 students per grade level to participate in the program. The counselors selected a total of 62 students who belonged to different peer groups and were perceived as possessing positive personal qualities such as maturity, leadership, and responsibility. After students were selected, the school counselor briefly met with each student to discuss potential interest in the program. The school counselor emphasized that they were chosen because adults in the school believed they had positive qualities and would make a difference. Of these, 53 students expressed interest in being part of the program. Interested students were sent home with an informed consent to be signed by a parent or caregiver and returned to the school counselor. A school counselor at each school followed up with a phone call to a parent or caregiver when necessary. Of these 53 parents or caregivers, 49 (93\%) provided written consent for their child to particpate. The school counselor then met with each of these students briefly to explain the research in more detail and collect student assent. All students with parental or caregiver consent assented to participate.

The final sample consisted of 49 students (55.1\% females and $44.9 \%$ males) enrolled in fourth through sixth grade. Participants ranged in age from 9-12 $(M=10.45$ and $S D=.87)$, with reported racial backgrounds $52.1 \%$ White, 22.9\% Hispanic, $8.3 \%$ Native American, 4.2\% African-American, and 12.5\% other. We conducted power calculations for the contrasts of interest. Power calculations indicated the study sample size should yield power of $\geq$ .90 to detect a medium effect size for the within factors effect (change from pre-and post-test) and $\geq .85$ to detect a medium effect size for the within-between factors interaction (grade as a moderator of program effects).

\section{Procedures}

Students completed a 75-minute training program during classroom time. The program was held in the school's library and was conducted by graduate students in a masters in counseling program. Participants completed pre- and post-tests to measure the effectiveness of the training program. The pre-test was conducted immediately prior to the program and the post-test was conducted immediately after the program. All study procedures were approved by the University Institutional Review Board.

\section{Instruments}

The Student-Advocates Pre- and Post-Scale (authors, in press) was used to measure the effectiveness of the STAC program. The questionnaire is comprised of 11 items that measure student-advocates' ability to identify bullying behaviors, knowledge of the STAC strategies, and confidence intervening in bullying situations. Examples of itmes include: "I know what verbal bullying looks like," "I know how to use humor to get attention away from the student being bullied," and "I feel confident in my ability to do something helpful to decrease bullying at my school." Items are on a 4-point Likert-type Scale ranging from "I totally disagree" to "I totally agree." The questionnaire has established content validity and adequate internal consistency for the total scale, $\alpha=.77$ (authors, in press). Subscales were created for this study to reflect the content domains Identification of Bullying Behavior (4 items), Knowlege of STAC Strategies (4 items), and Confidence Intervening (3 items). A Total Scale was created by summing all 11 items. For this sample, Chronbach's alphas were $\alpha=.81$ for the Total Scale, $\alpha=.76$ for Identification of Bullying Behavior, $\alpha=.67$ for Knowledge of STAC Strategies, and $\alpha=.71$ for Confidence Intervening.

\section{The STAC Strategies}

"Stealing the Show." "Stealing the show" involves using humor to turn students' attention away from the bullying situation. Trainers teach peer-advocates to use their sense of humor when they observe bullying to displace the attention away from the target. Trainers provide examples such as advocates could tell a funny joke or pretend to trip by acting silly.

"Turning it Over." "Turning it over" involves informing an adult about the situation and asking for help. During the training, students identify safe adults at school who can help. Students are taught to always "turn it over" if there is physical bullying taking place, or if they are unsure as to how to intervene. 
This is an author-produced, peer-reviewed version of this article. The final, definitive version of this document can be found online at Journal of Creativity in Mental Health, published by Routledge. Copyright restrictions may apply. doi: 10.1080/15401383.2016.1164645

“Accompany Others.” “Accompany others” involves the peer-advocate reaching out to the student who was targeted to communicate that what happened is not acceptable, that the student who was targeted is not alone at school, and that the peer- advocate cares about them. Trainers teach this to students by providing examples of how they can use this strategy such as approaching a peer after they were targeted and inviting them to go for a walk during recess.

“Coaching Compassion." "Coaching compassion” involves gently confronting the bully either during or after the bullying incident to communicate that his or her behavior is unacceptable. Additionally, the peer-advocate encourages the student who bullied to consider what it would feel like to be the target in the situation, thereby fostering empathy toward the target. Peer-advocates are encouraged to implement "coaching compassion” when they have a relationship with the student who bullied or if bully is in a younger grade and the peer-advocate believes they will respect them.

Program protocol. The STAC program was provided by counseling graduate students. The program included a didactic and an experiential role-play component (for details, see authors, in press). The didactic component included an audiovisual presentation with information about bullying and the STAC strategies followed by small group exercises to engage students. The experiential component consisted of dividing students into groups by grade level where they practiced the STAC strategies through role-plays that were developed in collaboration with an elementary school teacher. At the end of the program, each student shared a favorite STAC strategy, signed a "bullying stops with me" petition, and received a certificate of participation. After the program, the first author and a graduate student trainer met with peer-advocates monthly by grade to check-in, offer support, and brainstorm ways to effectively utilize the STAC strategies.

\section{Statistical Analyses}

We examined data for extreme case and for normality. We did not identify any outliers and all variables were within the normal range for skew and kurtosis. Four repeated measures analyses of variance (ANOVAs) were conducted to examine differences from pre- to post-test for the Total Score and subscales Identification of Bullying Behavior, Knowledge of STAC Strategies, and Confidence Intervening. The two independent variables were Time (pre-test; post-test) and Grade (fourth; fifth; sixth). Grade was included as an independent variable to examine grade as a moderator of intervention effects. All analyses were conducted at $p<.05$.

\section{Results}

Means, standard deviations, and contrasts for each outcome variable are presented in Table 1. Results of the repeated measures ANOVAs indicated a significant main effect for Time for the Total Scale score and the subscales Identification of Bullying Behaviors, Knowledge of STAC Strategies, and Confidence Intervening. Similarly, results indicated a significant main effect for Time $\mathrm{x}$ Grade for the Total Scale and the subscales Identification of Bullying Behaviors and Knowledge of STAC Strategies. In contrast, there was a statistical trend toward significant for the Time x Grade interaction for Confidence Intervening. Results indicate there was a significant increase in the Total Scale score and the three subscales for all grade level, although this was particularly true among fifth grade students (see Figure 1 as an example for the Total Scale).

\section{Discussion}

The purpose of this pilot study was to extend the literature by evaluating the immediate impact of a brief, stand-alone bystander program in an elementary school setting. Overall, results supported the STAC program as a promising method for equipping bystanders to be peer-advocates in addressing bullying in elementary school. As hypothesized, after completing the program, students reported a significant increase in their ability to identify what different types of bullying look like, knowledge of the STAC strategies, and general confidence intervening in bullying situations. In addition, results indicated that the program was most effective for fifth grade students.

Because bullying begins to escalate in late elementary school (Pellegrini \& Van Ryzin, 2011), it is important to identify effective bullying programs that school counselors can implement at the elementary school level. Despite comprehensive school- wide intervention programs being considered best practice for bullying intervention, these programs can be difficult to implement due to required resources. Thus, the STAC program can provide an alternative that is brief, cost-effective, and can be more accessible to a broader range of schools. 
This is an author-produced, peer-reviewed version of this article. The final, definitive version of this document can be found online at Journal of Creativity in Mental Health, published by Routledge. Copyright restrictions may apply. doi: 10.1080/15401383.2016.1164645

In addition, we examined if there was an optimal grade level for equipping students to be peer-advocates. We found that fifth grade students reported the greatest increase in ability to identify bullying behaviors and knowledge of the STAC strategies. They also reported the greatest increase in general confidence intervening, although this was a trend and did not reach statistical significance. These findings are consistent with research suggesting that students in fifth grade are well suited to be trained to intervene as peer-advocates in bullying situations (Sullivan \& Stoner, 2011). Although students display an increase in aggression in late elementary school, they also display an increased ability to learn alternative, prosocial behaviors such as the STAC strategies.

Limitations and Directions for Future Research

While this study contributes to our understanding of how to train elementary school students to intervene as peeradvocates against bullying, certain limitations should be considered. First, a relatively small sample size and largely White sample limit the generalizability of the results. Next, although the measure used in this study has established content validity and adequate internal consistency reliability, future studies using additional measures with established psychometric properties would strengthen the research examining the effectiveness of the STAC program. Additionally, information was obtained through self-report questionnaires, potentially leading to biased or distorted reporting, especially at the elementary school level. However, children are able to provide useful information about their experience when asked Likert-type questions in a manner that is meaningful to them (Christensen \& James, 2008). Therefore, the researchers read the surveys to students in an effort to increase the quality of the data.

Other limitations of this study concern the research design. First, this study did not include a control or comparison group. Thus, it is not clear if study outcomes were related to selection variables, the STAC intervention, or other unmeasured variables. Future research using a randomized controlled design would improve the validity of the study. Additionally, students were not randomly selected to participate in the study. Because we had school counselors select students to participate based on student attributes, outcomes may not generalize to different types of students. Finally, although the current study represents an important step in evaluating the effectiveness of a brief, stand-alone bystander program with elementary school students, this study did not examine the impact of the STAC program on the prevalence of bullying at school.

\section{$\underline{\text { Implications for School Counselors }}$}

This pilot study has practical implications for elementary school counselors. In addition to equipping elementary school students to be peer-advocates, unlike comprehensive, school-wide programs, the STAC program can be brief and cost effective, allowing schools to have access to program implementation on a broader scale. This stand-alone bystander program can also establish school counselors as leaders in program implementation, as this program does not require teachers to instruct students in the classroom setting. For schools with limited counseling resources, school counselors can work in partnership with a local counselor education program to implement the STAC strategies with the help of counseling students.

Because students in fifth grade may be developmentally primed to be trained to intervene, school counselors can place these students in a leadership role as peer- advocates. Fifth grade students can be assigned special tasks such as informally meeting with students in other grades regarding program implementation and brainstorming effective use of strategies. Additionally, fifth grade students can be encouraged to work as a team in implementing different strategies to address a bullying situation. Finally, fifth grade students can bring bullying situations to the attention of other peer-advocates, encouraging them to also intervene.

\section{Conclusion}

This pilot study evaluated the effectiveness of a brief, stand-alone bystander bullying program for elementary school students. Results indicated the STAC program was effective in increasing students' ability to identify different types of bullying behavior, knowledge of the STAC strategies, and general confidence intervening as a peer-advocate. Results provide preliminary support for the STAC program as a promising counselor-led approach that can be implemented with significantly fewer resources than comprehensive school-wide programs. 
This is an author-produced, peer-reviewed version of this article. The final, definitive version of this document can be found online at Journal of Creativity in Mental Health, published by Routledge. Copyright restrictions may apply. doi: 10.1080/15401383.2016.1164645

\section{References}

American Educational Research Association (2013). Prevention of Bullying in Schools, Colleges, and Universities: Research Report and Recommendations. Washington, DC.

Bradshaw, C. P. (2015). Translating research to practice in bullying prevention. American Psychologist, 70(4), 322332. doi:http://dx.doi.org/10.1037/a0039114 Christensen, P. M., \& James, A. (2008). Research with children: Perspectives and Practices. New York: Routledge.

Garrity, C., Jens, K., Porter, W., Sager, N., \& Short-Camilli, C. (2004a). Bully-proofing your school: Administrator's guide to staff development in elementary schools (3rd ed.). Longmont, CO: Sopris West.

Glew, G. M, Fan, M., Katon, W., Rivara, F. P., Kernic, M. A. (2005). Bullying, psychosocial adjustment, and academic performance in elementary school. Archives of Pediatric Adolescence \& Medicine, 159, 10261031. doi:10.1001/archpedi.159.11.1026.

Juvonen, J., Wang, Y, \& Espinoza, G. (2011). Bullying experiences and compromised academic performance across middle school grades. Journal of Early Adolescence, 31, 152-173. doi:10.1177/0272431610379415

Klomek, A. B., Marrocco, F., Kleinman, M., Schonfeld, I. S., \& Gould, M. S. (2011). Bullying, depression, and suicidality in adolescents. Suicide \& Life-Threatening Behavior, 4, 501-516, doi:10.1111/j.1943278X.2011.00046.x

Mariani, M., Webb, L., Villares, E., \& Brigman, G. (2015). Effect of participation in student success skills on prosocial and bullying behavior. The Professional Counselor, 5, 341-353. doi:10.15241/mm.5.3.341

Menard, S., \& Grotpeter, J. K. (2014). Evaluation of bully-proofing your school as an elementary school antibullying intervention. Journal of School Violence,13, 188-209. doi:10.1080/15388220.2013.840641

Pellegrini, A. D. \& Van Ryzin, \& M. J. (2011). Part of the problem and part of the solution: The role of peers in bullying, dominance, and victimization during the transition from primary to secondary school. In Espelage, D.L. \& Swearer, S.M. (Eds.), Bullying in North American Schools (pp. 91-99). New York: Rutledge.

Polanin, J. R., Espelage, D. L., \& Pigott, T. D. (2012). A meta-analysis of school-based bullying prevention programs' effects on bystander intervention behavior. School Psychology Review, 41, 47-65.

Rivers, I., Poteat, V. P., Noret, N., \& Ashurst, N. (2009). Observing bullying at school: The mental health implications of witness status. School Psychology Quarterly, 24, 211-223. doi:10.1037/a0018164

Rueger, S. Y., \& Jenkins, L. N. (2014). Effects of peer victimization on psychological and academic adjustment in early adolescence School Psychology Quarterly, 29, 77-88, doi: 10.1037/spq000036

Salmivalli, C., Voeten, M., \& Poskiparta, E. (2011). Bystanders matter: Associations between reinforcing, defending, and the frequency or bullying in classrooms. Journal of Clinical Child \& Adolescent Psychology, 40, 668676. doi:10.1080/15374416.2011.597090

Sullivan, R.B. \& Stoner, G. (2011). Developmental and gender differences in elementary school children's recognition of bullying. Pastoral Care in Education: An International Journal of Personal, Social, and Emotional Development, 30, 113-125.

U.S. Department of Health and Human Services (2015). StopBullying.gov. (n.d.). Retrieved June 1, 2015, from http://www.stopbullying.gov/ 